\title{
The Great Debates
}

\section{The Great Debates}

The following papers evolved as a continuing discussion begun by John Harris in his paper "Stem Cells, Sex, and Procreation" (CQ Vol 12, No 4). First, Julian Savulescu responds to the Harris paper, with Harris following with a response to Savulescu. Next, the two authors suggested a joint paper in which, despite their continuing differences, they would examine where they agree. This remarkable collection of papers, presented here, is a rare opportunity to follow the developing thoughts of two of today's most influential philosophers through what they describe as "a somewhat tortuous process of reason and argument." They test their own positions as they challenge the views of the other, and they discover points at which their intellectual paths converge.

This Harris-Savulescu debate illustrates the value of sharing publicly the sorts of philosophical wrestling and metamorphosis that usually remain private. As they observe in the conclusion of "The Creation Lottery":

Bioethics is disappointing for its lack of constructive dialogue. Bioethics is not about conversion (that is the province of religion) or convincing others that one is right. It is about discovery of the truth and gaining knowledge. Sometimes it requires the revision of one's own beliefs.

There could be no better example for the rest of us than to watch this process in action. For this reason and in tribute to Harris and Savulescu, CQ is inaugurating "The Great Debates" series, in which noted bioethicists will debate in these pages some of the most perplexing contemporary bioethics issues.

\section{Embryo Research: Are There Any Lessons from Natural Reproduction?}

\section{JULIAN SAVULESCU}

John Harris gives a comprehensive and generally valid defense of embryo research. Although nearly all his arguments are valid, one-the argument comparing natural reproduction to embryo research-is problematic in several important ways. I focus here on that argument. 
Harris begins his provocative paper ${ }^{1}$ in this way:

I make two appeals to consistency, or to "parity of reasoning," that I believe show that no one who either has used or intends to use sexual reproduction as their means of procreation, nor indeed anyone who has unprotected heterosexual intercourse, nor anyone who finds in vitro fertilization (IVF) acceptable, nor anyone who believes that abortion is ever permissible can consistently object on principle to human embryo research nor to the use of embryonic stem cells for research or therapy. (p. 353, and see notes cited therein)

Harris is concerned with "consistency [of treatment] of stem cell research with what is regarded as acceptable and ethical with respect to normal sexual reproduction (p. 361)" Harris makes four (not two, as he claims) appeals to parity of reasoning about embryo research and

1. engaging in sexual reproduction

2. intending to engage in sexual reproduction

3. IVF, and

4. abortion.

Although his arguments for the third and fourth are successful, his arguments for the first and second fail. I will argue that the lessons from natural reproduction are different from those that Harris wishes to draw.

The following is Harris's argument in full.

Let us start with the free and completely unfettered liberty to establish a pregnancy by sexual reproduction without any "medical" assistance. What are people and societies who accept this free and unfettered liberty committing themselves to? What has a God who has ordained natural procreation committed herself to?
We now know that for every successful pregnancy that results in a live birth many, perhaps as many as five, [note 47: Robert Winston gave the figure of five embryos for every live birth some years ago in a personal communication. Anecdotal evidence to me from a number of sources confirms this high figure, but the literature is rather more conservative, making more probable a figure of three embryos lost for every live birth. See: Boklage CE. Survival probability of human conceptions from fertilization to term. International Journal of Fertility 1990; 35(2)75-94. See also: Leridon H. Human Fertility: The Basic Components. Chicago: University of Chicago Press; 1977. Again, in a recent personal communication, Henri Leridon confirmed that a figure of three lost embryos for every live birth is a reasonable conservative figure.] early embryos will be lost or "miscarry" ...

How are we to think of the decision to attempt to have a child in the light of these facts? One obvious and inescapable conclusion is that God and/or nature has ordained that "spare" embryos be produced for almost every pregnancy and that most of these will have to die in order that a sibling embryo can come to birth. Thus, the sacrifice of embryos seems to be an inescapable and inevitable part of the process of procreation. It may not be intentional sacrifice, and it may not attend every pregnancy, but the loss of many embryos is the inevitable consequence of the vast majority (perhaps all) pregnancies. For everyone who knows the facts, it is a conscious, knowing, and therefore deliberate sacrifice; and for everyone, regardless of "guilty" knowledge, it is part of the true description of what they do in having or attempting to have children.

We may conclude that the production of spare embryos, some of which will be sacrificed, is not unique to assisted reproduction technologies (ART); it is an inevitable, (and presumably acceptable, or at least tolerable?) part of all reproduction. 
Both natural procreation and ART involve a process in which embryos, additional to those that will actually become children, are created only to die. I will continue to call these "spare" embryos in each case. If either of these processes is justified it is because the objective of producing a live healthy child is judged worth this particular cost. (p. 362)

Harris argues that there is no difference between intending to bring about an outcome and merely foreseeing it. One example he gives is that it would be wrong to use a mobile phone near a pregnant woman if using that phone exposed the woman to a high chance of having a miscarriage.

For Harris, if

- an act that has the foreseeable consequences of bringing into existence a new life and causing the death of four embryos is permissible, then

- an act that has the foreseeable consequences of saving an existing life and causing the death of four embryos is permissible.

Harris assumes, plausibly, that we have as much reason to save an existing life as we do to bring a new life into existence. He also assumes, again plausibly, that embryo research will result in the saving of existing lives.

\section{Where This Argument Fails}

\section{Nonmaleficence}

Harris's mobile phone example is important. The mobile phone user in his example violates a principle of nonmaleficence. Nonmaleficence is usually defined as "not harming." But we should clarify or extend this definition to include not exposing people to unreasonable risks of harm. The moral of the mobile phone story is that we should not expose people to unreasonable risks.

Does natural reproduction expose the embryo to unreasonable risks? If the embryo is not a person with rights, the question is redundant. But Harris, although he believes the embryo is not a person, attempts to set this issue aside. He is trying to get leverage on those who may believe the embryo is a person but nonetheless believe natural reproduction is permissible despite the high embryo wastage it entails.

It is debatable whether natural reproduction imposes any risk at all on any embryo. The risk of dying (let us assume it is $80 \%$ ) is inherent to the embryo's nature. It is not as if the same embryo could have been created without that chance of dying.

Let us assume for argument's sake, however, that natural reproduction can be said in some sense to have imposed an $80 \%$ chance of dying on the embryo. This is very high. If I gave you a drug that had an $80 \%$ chance of killing you, I would be acting very wrongly. But in deciding whether this risk is reasonable to impose on the embryo, we must ask what the alternative is. In the embryo's case, the alternative is nonexistence. A $20 \%$ chance of a good life is better than nonexistence. So, the imposed risk, if there is one, is reasonable.

Consider the sick child analogy. Imagine your child is certain to die of a disease in a remote village in Africa (option A). Instead of certain death, you could undertake a journey in which there is a four-fifths chance of being killed by natives. But if you make it to the city, there is a hospital where your child can be cured (option B).

Option B is better than option A. Taking the journey imposes an $80 \%$ chance of being killed, but this risk is reasonable compared to certain death.

If the risk is reasonable when the alternative is death, then it is also rea- 
sonable when the alternative is nonexistence. Some might object to this. Consider the genetic disorder analogy. Both members of a couple have a rare genetic disorder such that any child of theirs is certain to be born with a genetic condition. The child will develop in utero, but this condition has an $80 \%$ mortality immediately after birth. However, if the child survives, it will likely be normal.

Some people believe that it is wrong to knowingly conceive a child with a high chance of having a severe genetic condition. Before the advent of prenatal diagnosis, some couples, having discovered they are at risk of having a child with a genetic disorder, chose to refrain from having more children. These couples believed it was better not to have a child than to have a child with a severe genetic disorder.

It is not clear whether these couples were rational or right in choosing to remain childless rather than risk having a child with a disorder. However, even if it is permissible, right, or rational to do as these couples did, this does not bear on the genetic disorder analogy or natural reproduction for two reasons. First, they may have been right because it was in their interests not to have a child with such a disorder. However, if a couple wish to have a child with genetic disorder, it may be in their interests to have such a child. Second, the child in these scenarios was likely to live with a severe genetic condition and severely impaired quality of life. In both the genetic disorder analogy and natural reproduction, the condition is possibly lethal but does not affect quality of life if the human survives. It may be wrong to bring into existence a child who will suffer enormously. It is not clearly wrong to bring into existence a child who merely has a low chance of surviving but will likely otherwise have a very good life.
Natural reproduction gives every embryo the greatest chance it could have of becoming a baby. And that baby has a high chance of having a good life. The principle that drives intuitions about the wrongness of mobile phone use in Harris's example does not bear on natural reproduction at all. Although the risk of an embryo dying in natural reproduction is high, perhaps as high as $80 \%$, it is the lowest it could be.

This is quite different from embryo research. Embryo research imposes new risks on embryos either created as part of infertility programs or specifically for research. I will next examine whether this risk is reasonable or unreasonable.

\section{Instrumentalization}

Harris claims that Catholics and prolife advocates "are treating the 1-4 embryos that must be sacrificed in natural reproduction as a conscious (though not intended) means to have a live birth" (p. 364).

This may be so. It is important to distinguish, however, between being treated as a means and as a mere means (as Harris himself has done in many of his other articles). Kant's dictum is that one should treat human beings always as an end, never merely as a means. It is only the latter that Kantians object to and that represents instrumentalization.

Here is the difference between being treated as a means (and also as an end) and being treated as a mere means:

- A couple want to have a child, so they create an embryo. They do everything they can to help that embryo become a baby, but, alas, it dies from natural causes. They treated it as a means to having a child but also did everything they could to help it to survive, and so also treated it as an end in itself. 
- A couple have a sick child who will die without a bone marrow transplant. So, they create an embryo for the purpose of destroying it for its stem cells. This treats the embryo as a mere means to securing the health of their existing child (assuming, as I have been, that the embryo has rights and interests).

Creating embryos by natural reproduction does not instrumentalize them as mere means even if they are highly likely to die.

Harris claims, "Given that decisions to attempt to have children using sexual reproduction as the method (or even decisions to have unprotected intercourse) inevitably create embryos that must die ..." (p. 363). This is false. Some people fall pregnant the first time they try to have a child. These acts of sexual reproduction do not create embryos that must die. So, it is not inevitable that engaging in sexual reproduction results in embryos that must die, even if it is highly likely.

Harris gives an example of what he believes is instrumentalization:

A woman has two fertilized eggs and is told it is certain that if she implants both only one will survive but that if she implants only one it will not survive. Would she be wrong to implant two embryos to ensure a successful singleton pregnancy? (p. 364)

This is not instrumentalization. What is characteristic about instrumentalization is that it reduces the chance of an embryo surviving for some other purpose. In this case, however, there is no such reduction in risk. Both embryos have the greatest chance of surviving that they could have. Each is in this way treated as an end in itself, even if this is a means to increasing the chances of a couple having a baby.
Harris gives another example of instrumentalization:

Suppose that for some biological reason there was a condition that required that, for one embryo to implant, it was necessary to introduce a companion embryo that would not, and we could tell in advance which would be which. (p. 365)

This is not instrumentalization, either. Again, each embryo has the greatest chance it could have of surviving. The fact that there is another benefitincreasing the chance of another embryo surviving or the couple having a baby-does not compromise this.

To put the issue in the plainest possible terms, we need to distinguish two ways in which embryos perish in order that a live child is born:

1. Each embryo has a one in five chance of becoming a child.

2. An embryo, A, would not form a child normally. However, if another four embryos, B-E, were destroyed and cells taken from these and inserted into the first, then the first would definitely survive. (This mirrors the situation of multifetal reduction in which a woman has quintuplets. All five babies are likely to die. But if four are killed, the remaining one has a high chance of surviving.)

The first does not involve instrumentalization; the second does. But the second is not what happens in nature.

Consider a case of true instrumentalization. Imagine that embryos have a $20 \%$ chance of surviving. Imagine that, by splitting an embryo, we give each embryo a $15 \%$ chance of becoming a baby. If both are implanted, the chance of having at least one live born child is $27.75 \%$. This increases the chance of having a baby. But $\mathrm{A}$ is 
destroyed and replaced by two qualitatively identical embryos B and C, each of which has a lower individual chance of producing a baby. This instrumentalizes embryo A for the couple's purpose of having a baby. Whether it is wrong is another question. But natural reproduction does not involve any such instrumentalization.

Harris frequently uses the term "sacrifice" - but no embryos are sacrificed in natural reproduction. Each gets the greatest chance it could have of living. Sacrifice implies instrumentalization-sacrifice for some purpose.

"Both natural procreation and ART involve a process in which embryos, additional to those that will actually become children, are created only to

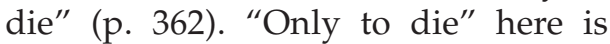
ambiguous-it could mean "but do die." Or it could be used in the sense "only for the purpose of dying." Talk of embryos dying for other embryos and sacrifice suggests the latter interpretation, which is false. In the case of natural reproduction, these embryos are not created for the purposes of giving other embryos a greater chance of life-every embryo gets the best and equal chance of being a baby.

Harris's claim that embryos in assisted reproduction are instrumentalized (as mere means) is also not entirely correct. In assisted reproduction, a batch of embryos is created at one time. Then each embryo in that batch has some chance of surviving, albeit lower than if fewer embryos had been created or if it had be conceived naturally. However, it is not created only to die. It is a lottery that embryos do die.

\section{Existing versus New Lives}

Let us return to Harris's central argument. Recall that, for Harris, if

- an act has the foreseeable consequences of bringing into exis- tence a new life and causing the death of four embryos is permissible, then

- an act that has the foreseeable consequences of saving an existing life and causing the death of four embryos is permissible.

This argument fails because Harris fails to consider the alternative courses of action. Comparing saving with bringing into existence:

1. We have as much reason to save existing lives as we have to bring new lives into existence.

2. It is reasonable to act so that four embryos die to bring one new life into existence, when the alternative is having no children at all.

3. It is reasonable to act so that four embryos die to save one life, when the alternative is that none live.

4. It is reasonable to act so that four embryos die to save one life, when the alternative is that one person dies and each of four embryos has a $20 \%$ chance of surviving.

The third may follow from the first and second. However, the fourth does not follow from the first and second or from the first, second, and third.

Consider another thought experiment. Imagine that infant mortality is very high $-80 \%$ of infants born die of natural causes. Harris's argument would also apply to this case, if we accept a prolife view of the embryo's moral status:

- Natural reproduction entails that it is acceptable for four infants to die to bring a new life into existence. (P1)

- There is at least as strong a moral reason to save existing lives as there is to bring new lives into existence. (P2)

- If it is permissible for four infants to die to bring one new life into 
existence, then it is permissible for four infants to die to save one existing life. (conclusion)

It would not be permissible to kill four healthy infants to save one existing life-so the argument is invalid. Harris has assumed, for argument's sake, that the embryo has a right to life. If that is so, the healthy embryo or infant has the same right to life as anyone else. So, it cannot be right to kill embryos for research. Alternatively, Harris has merely assumed that the embryo does not have a full moral status, in which case he is begging the question (or assuming what he set out to prove). In that case, his argument would prove nothing.

\section{Embryonic Stem Cell Research on Spare Embryos}

I am told that men are often blind to the faults of a beautiful woman. Harris is overly attracted by the sexiness of the analogy with natural reproduction. However, Harris's approach of appealing to consistency can be resuscitated and applied to spare embryos.

What are spare embryos?

Ten percent of couples are infertile, and IVF has offered these people the opportunity to have a child. It is an accepted part of IVF that more embryos are produced than a couple may need. These embryos are then frozen to reduce risks to the woman of numerous attempts to obtain eggs from her body, which can cause illness or death. Prior to embryo freezing, several embryos are transferred to the woman at one time, which leads to the high rates of mortality and disability associated with triplets or quadruplets. The consequences of not freezing embryos would be that women would be harmed and children born by IVF would be worse off.
That is why we have about 70,000 frozen embryos in Australia and more in countries like the United Kingdom.

Society has made the decision that it is acceptable to reduce the risk to existing women by creating excess embryos. If embryos can be created and destroyed to reduce the risks to women who are infertile, then it would be reasonable to create and destroy embryos to reduce the risk to the health of other people-that is, those who may benefit from stem cell therapies.

If we accept IVF and the production of spare embryos as a part of infertility treatment, we should accept the creation of new embryos as part of the research into embryonic stem cells.

\section{Embryo Research and Unreasonable Risk}

What are the true lessons from natural reproduction? The main lesson is that imposing risks on the embryo can be acceptable if it is the best strategy to improve the chances of that embryo having a healthy, happy life as a person. I have argued elsewhere that in certain conditions, some destructive embryo research is the best strategy to maximize the chances of a population of embryos surviving to live a reasonable life.

Does destructive research impose unreasonable risk on the embryo? There are two ways in which we can avoid violating a principle of nonmaleficence. The first is to argue that the embryo is not the kind of being that can be harmed by being killed. This is to deny that the embryo has a moral status.

The second is to argue that the embryo that is killed has not been exposed to an unreasonable risk. I have argued, after Harris, ${ }^{2}$ that if the embryo is a part of a population of embryos that will benefit from the practice of killing some, then killing may not be 
wrong. ${ }^{3}$ Whether it is wrong turns on the fraction of ART embryos that are killed and what the benefits are to that population. If stem cell therapies will benefit that population in significant ways, then this may be enough to justify killing some.

\section{Unreasonable Risks}

I have so far been considering what constitutes a reasonable risk to impose on an embryo from the embryo's own perspective (assuming it has one). In fact, society imposes very unreasonable risks on embryos all the time. All preimplantation genetic diagnosis and virtually all prenatal testing work against the interests of the embryo tested. Not only is there some risk of harm to the embryo directly, but the only decision that can be made on the basis of these tests that will affect the outcome of the pregnancy is to kill the embryo. Genetic testing is not done for the embryo's sake but for the couple's sake. Indeed, couples are, in prac- tice, allowed to authorize the killing of embryos and fetuses for many reasons. The reason these practices are permissible is that the embryo has no perspective, and no rights or interests, because it is not a person. Not only are we permitted to expose embryos to reasonable risks, but, if we are consistent with other social practices, we can expose embryos to any risk in research, provided they are not allowed to live on in a damaged state. If we are consistent, as Harris urges us to be, any kind of destructive embryo research-including creating new embryos by IVF or cloning-is permissible.

\section{Notes}

1. Harris J. Cambridge Quarterly of Healthcare Ethics 2003;12(4):353-71.

2. Harris J. Survival lottery. In: Harris J, ed. Bioethics. New York: Oxford University Press; 2001:300-15.

3. Savulescu J. The embryonic stem cell lottery and the cannibalization of human beings. Bioethics 2002;16(6):508-29.

\title{
Sexual Reproduction Is a Survival Lottery
}

\author{
JOHN HARRIS
}

I have argued that because human sexual reproduction inevitably involves the creation and destruction of embryos, it is a problematic activity for those who believe that the embryo is "one of us." ${ }^{1}$ Or, if it is not a problematic activity, then neither is the creation and destruction of embryos for a

Søren Holm has been an important source of ideas for this paper. Julian Savulescu has also been very generous in commenting in detail on this paper, and I have taken account of the critique that I have received. purpose of comparable moral seriousness-the development of lifesaving therapy, for example. I assume that, whereas it is possible for the very first act of unprotected intercourse to result in a live human baby, and hence not in a given case cause any embryo loss, this is a rare event and that, statistically, for every live birth from three to five embryos must be created only to die. ${ }^{2}$ For dramatic effect, I assume that five is a reasonable figure, giving each embryo a $20 \%$ chance of survival; how- 
ever, nothing in the argument depends on any specific figures being correct.

Julian Savulescu thinks I am wrong about this ${ }^{3}$ and says so forcefully in a paper that is full of original, inventive, and arresting arguments. I cannot deal with all the points Savulescu makes, but I will look here at the most material; and to be faithful, I quote Savulescu in full, not least because in the quotation he develops some elements of my argument that are needed for an understanding of the issues:

Harris argues that there is no difference between intending to bring about an outcome and merely foreseeing it. One example he gives is that it would be wrong to use a mobile phone near a pregnant woman if using that phone exposed the woman to a high chance of having a miscarriage.

For Harris, if

- an act that has the foreseeable consequences of bringing into existence a new life and causing the death of four embryos is permissible, then

- an act that has the foreseeable consequences of saving an existing life and causing the death of four embryos is permissible.

Harris assumes, plausibly, that we have as much reason to save an existing life as we do to bring a new life into existence. He also assumes, again plausibly, that embryo research will result in the saving of existing lives....

Harris's mobile phone example is important. The mobile phone user in his example violates a principle of nonmaleficence. Nonmaleficence is usually defined as "not harming." But we should clarify or extend this definition to include not exposing people to unreasonable risks of harm. The moral of the mobile phone story is that we should not expose people to unreasonable risks.... .

It is debatable whether natural reproduction imposes any risk at all on any embryo. The risk of dying (let us assume it is $80 \%$ ) is inherent to the embryo's nature. It is not as if the same embryo could have been created without that chance of dying.

Let us assume for argument's sake, however, that natural reproduction can be said in some sense to have imposed an $80 \%$ chance of dying on the embryo. This is very high. If I gave you a drug that had an $80 \%$ chance of killing you, I would be acting very wrongly. But in deciding whether this risk is reasonable to impose on the embryo, we must ask what the alternative is. In the embryo's case, the alternative is nonexistence.

These are rich passages, and many issues are raised. As Savulescu notes, "the moral of the mobile phone story is that we should not expose people to unreasonable risks." I agree; but Savulescu assumes the following definition of reasonable risk: "risks on the embryo can be acceptable if it is the best strategy to improve the chances of that embryo having a healthy, happy life as a person."

I agree with Savulescu that, if the alternative is nonexistence, a rational embryo would wish to run the risk of death, or less problematically, it is a risk that represents a "good bet" for the embryo because it offers that embryo's only chance of a worthwhile life. ${ }^{4}$ However, the issue is not what risks it would be rational for an embryo to take but what those who think that the embryo is "one of us" are entitled to do to fellow humans. Can Catholics, or those who defend a so-called prolife position (hereafter collectively termed "embryo rightists"), ${ }^{5}$ believe that the embryo is one of us and, consistently with their morality, voluntarily impose such a high probability of untimely death?

I introduced the mobile phone example for a rather different purposenamely, to show that the intentions of 
the agent do not make a scrap of moral difference and that the doctrine of double effect had no purchase on these cases. Savulescu is therefore right, but wrong, that " $[t]$ he principle that drives intuitions about the wrongness of mobile phone use in Harris's example does not bear on natural reproduction at all." My suggestion was that, if we know that using a mobile phone within 50 meters of a pregnant woman involves a high probability of causing miscarriage, then we are responsible for that miscarriage and mobile phone use would probably be indefensible in circumstances in which it might pose such a risk. He is right that it is unlike natural reproduction, because mobile phone use in no way serves the embryo's interests; but wrong because it does illustrate a different point about what is involved in natural reproduction-namely, that, once you know that an activity causes harm and you persist in that activity, you are responsible for the harm caused, irrespective of your intentions or hopes about whether harm will occur. This was and is a main part of my argument, and the purpose of the mobile phone example was primarily to illustrate this "truth."

\section{Instrumentalization}

In taking me to task for my imperfect understanding of the idea of what is wrong with instrumentalization, Savulescu says:

Harris claims that Catholics and prolife advocates "are treating the 1-4 embryos that must be sacrificed in natural reproduction as a conscious (though not intended) means to have a live birth."

This may be so. It is important to distinguish, however, between being treated as a means and as a mere means (as Harris himself has done in many of his other articles). Kant's dictum is that one should treat human beings always as an end, never merely as a means. It is only the latter that Kantians object to and that represents instrumentalization.

Here is the difference between being treated as a means (and also as an end) and being treated as a mere means:

- a couple want to have a child, so they create an embryo. They do everything they can to help that embryo become a baby, but, alas, it dies from natural causes. They treated it as a means to having a child but also did everything they could to help it to survive, and so also treated it as an end in itself.

- a couple have a sick child who will die without a bone marrow transplant. So, they create an embryo for the purpose of destroying it for its stem cells. This treats the embryo as a mere means to securing the health of their existing child (assuming, as I have been, that the embryo has rights and interests).

Creating embryos by natural reproduction does not instrumentalize them as mere means even if they are highly likely to die.

Harris claims, "Given that decisions to attempt to have children using sexual reproduction as the method (or even decisions to have unprotected intercourse) inevitably create embryos that must die ..." This is false. Some people fall pregnant the first time they try to have a child. These acts of sexual reproduction do not create embryos that must die. So, it is not inevitable that engaging in sexual reproduction results in embryos that must die, even if it is highly likely.

Let me deal with the point of agreement first. Savulescu is again almost right when he says:

This is false. Some people fall pregnant the first time they try to have a 
child. These acts of sexual reproduction do not create embryos that must die. So, it is not inevitable that engaging in sexual reproduction results in embryos that must die, even if it is highly likely.

I say "almost right" because I meant that the social practice of sexual reproduction involving, as it does, "decisions to attempt to have children using sexual reproduction as the method (or even decisions to have unprotected intercourse) inevitably create embryos that must die." This is true even though in individual sexual practice some rare successful pregnancies occur "first time" and were not preceded or indeed followed by acts of intercourse that result in early miscarriage. This can happen, but I doubt there are many instances! The issue is not whether a successful pregnancy can or cannot result from a single act of intercourse, because obviously it can; but whether the institution of sexual reproduction is one that inevitably causes the deaths of large numbers of embryos and is therefore one that embryo rightists should think wrong.

\section{Means, and Mere Means}

Again, Savulescu is right when he says "it is important to distinguish between being treated as a means and as a mere means." This is something on which, as he notes, I have always insisted. However, experience has taught me that, whereas I always insist on this distinction, those who most commonly employ it in these contexts almost never pay attention to this distinction or they use it where, as is usually the case in human reproduction, there are multiple purposes at play, some purely instrumental and others not. ${ }^{6}$ Savulescu sets out this distinction in his lead-in to the bullet points, saying, "Here is the difference between being treated as a means (and also as an end) and being treated as a mere means." 7 If he had been a touch more meticulous, he would have said, "Here is a difference," for there are many other plausible ways of drawing this distinction. Savulescu offers a particular interpretation, or rather illustration, of the concept of "instrumentalization" and one that also has its problems.

Savulescu uses two different ideas to get at this concept. The first concerns what people want or try to achieve:

They do everything they can to help that embryo become a baby, but, alas, it dies from natural causes. They treated it as a means to having a child but also did everything they could to help it to survive, and so also treated it as an end in itself.

I am far from convinced that simply doing everything possible, at a certain stage in the proceedings, to help the embryo become a baby is nearly enough to avoid a telling charge of instrumentalization or of using the embryo as a mere means.

Suppose that reproduction worked in the following way. A cycle in which an embryo would miscarry was always followed by a cycle in which an embryo would go to term. Then, despite the parents doing "everything they can to help that embryo to become a baby," treating "it as a means to having a child but also [doing] everything they could to help it to survive, and so also treat[ing] it as an end in itself," it would nonetheless have been treated instrumentally-as a mere means because, despite the best endeavors and the hopes and intentions of the parents, it could not in those circumstances be other than a means. The only reason for conceiving an embryo in cycle one would be as a precursor to the subsequent successful preg- 
nancy. This shows that willingness to do everything possible to help the embryo survive is not sufficient to exculpate the agents from the charge of instrumentalization. Indeed, it would be difficult for anyone to claim with a straight face that they did not in such circumstances fully intend the death of the first embryo. ${ }^{8}$ And indeed, I do not believe that if these were the facts of life there would be a wholesale abandoning of sexual reproduction by embryo rightists.

Savulescu insists that in this case "the embryo is not harmed. The parents could conceive it, hoping for a miracle. It is not a mere means, whereas killing an embryo to take its stem cells to treat another embryo would constitute instrumentalization, would be using it as a mere means." 9

There are two issues here; one is what we mean by "harming." Savulescu seems to be relying on the idea that harm means "made worse off than it would otherwise be." This is a classic account of harm used most influentially by Joel Feinberg. ${ }^{10}$ However, I have argued elsewhere that this conception of harm is incomplete and that, where an individual is in a harmed condition (disabled or suffering) and someone else is responsible for the individual being in that condition, then they have harmed that individual in the relevant sense. This account applies most aptly to so-called wrongful life cases, where parents are allegedly responsible for their child being born in a harmed condition, even though there was no alternative for that particular child except nonexistence. ${ }^{11}$ I think this is the situation here, where the parents have chosen to have a child they know will be born in a harmed condition - in this case, a condition in which it cannot surviveand are responsible for that condition precisely because they could have chosen not to have this child. ${ }^{12}$ Savulescu argues that this implies that all cases of natural reproduction are cases, on this argument, of bringing a child into existence in a harmed state. He claims that, on this argument, being created with an $80 \%$ chance of dying (as all embryos, we are assuming for the purposes of argument, have) is creating an embryo in a harmed state. This is correct. I had drawn a distinction between harming and wronging such that not all instances of harming are also instances of wronging. In this case, the embryos are harmed because they are produced fully voluntarily in a harmed condition, but they are not wronged. The distinction between harming and wronging that I draw requires that, for harming also to constitute wronging, the harm must be contrary to the interests of the individual harmed. Both Savulescu and I think that this is not the case here because the embryos do not have relevant interests in life. However, and this is the point, embryo rightists do not agree with us about this. For them, these should be cases of wrongful life because embryos are unnecessarily brought into being in a harmed condition that is, moreover, one in which they cannot survive. $^{13}$

Imagine conjoined twins, Tom and Dick, who share a heart. Both will die, let us say within a year, if not separated immediately. It is equally easy to save either, but both cannot survive separation. The parents decide to save Tom, although even as Dick dies they want him to live and do "everything they can to help" him survive. His death is instrumental to the independent existence of Tom despite these heroic but futile efforts. ${ }^{14}$ In this case, by deciding to have the operation to separate the twins when they did, the parents have killed Dick.

This case, like those of embryos, raises the question of how to characterize instrumentalization in cases 
where the individual allegedly instrumentalized is not competent to consent for himself. Where the individual can consent and does so, there is usually no scope for the claim that the individual consenting to being part of someone else's project has been instrumentalized. In such a case, they have thereby adopted their role in another's project as a project of their own. Absent the possibility of consent, we have to find another symptom or sign of instrumentalization. ${ }^{15}$ Savulescu suggests that the relevant idea might be "harming one individual for the benefit of another." I agree that this is one likely candidate for the further elaboration of the concept of instrumentalization absent a possibility of consent. The question between us is whether this has happened in the case of Tom and Dick, or for that matter in other cases. In the case I have put, Savulescu imagines that Tom and Dick would die in one second and comments "nothing different of moral relevance has happened to Dick - he is dead in both cases." 16 He and I agree about this, and I imagine most others would as well. However, imagine that Tom and Dick are 3 months old at the time of the operation and might have survived conjoined for a further 12 months. I imagine Savulescu would still find the operation to separate them justified; I certainly do. ${ }^{17}$ Embryo rightists and indeed many others would disagree, however. Dick has been deprived of up to 12 months of life. If we go back to the embryos, we have to decide what embryo rightists would think (or ought to think) about creating embryos that must die, given what they believe about the rights and interests of embryos.

So, we are left with Savulescu's second idea. This he develops in the following way:

Harris gives an example of what he believes is instrumentalization: "A woman has two fertilized eggs and is told it is certain that if she implants both only one will survive but that if she implants only one it will not survive. Would she be wrong to implant two embryos to ensure a successful singleton pregnancy?"

This is not instrumentalization. What is characteristic about instrumentalization is that it reduces the chance of an embryo surviving for some other purpose. In this case, however, there is no such reduction in its chances in this case. Both embryos have the greatest chance of surviving that they could have. Each is in this way treated as an end in itself, even if this is a means to increasing the chances of a couple having a baby.

Savulescu seems to be relying on the idea that both embryos have the greatest chance of surviving that they could have to show that they have not in fact been instrumentalized. This does not seem to me to defeat the idea of instrumentalization, however. To use an individual as an instrument is to use her as a means to an end and not an end in herself. In my example, one embryo is inevitably used as a means to the survival of the second, despite the wishes or hopes of any third parties, including the parents, that she also survives and despite the fact that this is the best chance for that embryo. The woman implants two because she knows it is the best way to maximize the survival chances of one of them. She wants both to survive but, because she knows and accepts that one will die and still goes ahead, she accepts the death of one of the embryos as a price she (and it) must pay to achieve the birth of a child. It does not matter (or if it does, Savulescu nowhere shows that it does) that we do not know in advance which of the two embryos must die. This is a perfectly reasonable and sensible way of understanding instrumentalization, although it is not Savulescu's way. It is consistent 
with Kant's idea of using an individual as a mere means. Of course, neither Savulescu nor I think that it would be wrong for the woman to act in this way; but embryo rightists, or those who classically employ the Kantian dictum, as Savulescu calls it, often do. ${ }^{18}$ Savulescu concedes that, whereas this may constitute instrumentalization he does not believe that it could amount to "wrongful" instrumentalization. This is an interesting distinction that he does not further elaborate. I believe it constitutes instrumentalization in the sense disapproved of by Kant and embryo rightists-namely, using the embryos in question merely or primarily as a means. Of course, neither Savulescu nor I think that this is wrongful, but again, I believe the embryo rightists, who are my target, do (or should do if they are consistent).

Consider a public health measure like vaccination against a deadly disease where there is a significant death rate from vaccination but less than would happen in the population without vaccination. Here we both agree that vaccination is fully justifiable. Although the public health authorities do not want anyone to die, from their perspective the inevitable vaccination causalities are purely instrumental. They are a means to public health; they are a price deemed worth paying for the sake of the gain. What of the parents' decision to vaccinate their particular child? Here things are more complicated, but it is not clear that even here the parents are not in part treating their child instrumentally, because of the free-rider problem. The free-rider problem is this: where most people are vaccinating their children, it is in the interests of any particular child and their parents not to be vaccinated and to ride free on the backs of the beneficial so-called herd effect that protects all, because most are vaccinated. If, despite the fact that they could be free riders, individual parents have their child vaccinated, they are taking a public health perspective and to that extent treating their child instrumentally, as a means to public health, despite the fact that they are possibly also motivated by fairness to other families.

Savulescu frequently objects to my use of the term "sacrifice" in connection with embryos that die in natural reproduction. He says:

\section{Harris frequently uses the term "sacrifice" - but no embryos are sacri- ficed in natural reproduction. Each gets the greatest chance it could have of living. Sacrifice implies instrumental- ization-sacrifice for some purpose. However, the fact that each embryo- "gets the greatest chance it could have of living" does not, as I have dis- cussed, negate the idea of sacrifice nor the idea of instrumentalization. ${ }^{19}$}

Suppose there is a genotype that enables an embryo to go to term but that it will surely die shortly after birth, at which point its organs can be safely harvested; the baby being, let us assume, on life support long enough to effect safe harvesting. I need vital organs for my existing child and as "luck" ${ }^{20}$ would have it, preimplantation genetic diagnosis shows that one of my in vitro embryos has this condition. I choose to implant this embryo. Although I give this embryo "the greatest chance it could have of living" and it is, as Savulescu says, "in this way treated as an end in itself," it is difficult, I suggest, not to see it as having been used instrumentally. Not, of course, as Savulescu uses the term "instrumentalization" but, as I have argued, in a perfect defensible sense of that term.

\section{Antecedent and Actual Interests}

There is an important distinction between antecedent and actual inter- 
ests that is relevant here. I borrowed it from Ronald Dworkin a long time ago:

In discussing the implausibility of enforcing antecedent interests in the name of consent, Ronald Dworkin uses an interesting illustration that is germane here. He asks us to imagine something like the following scenario. If I possess a lottery ticket which I bought for one pound, it may be in my interests antecedently to the draw, to sell the ticket to you for one hundred pounds. However once the draw has taken place and I have won a million pounds, it cannot be just for you to force me to surrender the ticket for one hundred pounds even if is true that I would have consented to sell it to you for that sum had you asked me antecedently to the draw. So even judgements about antecedent interests which are conceded, by the relevant agent, to be entirely accurate, provide no adequate reason for enforcing decisions which are not in an agent's actual interests.

The natural lottery of health ... is surely like this. Even if it were true that I would have consented to a particular distribution of health resources before I know what I need; it does not follow that it would be fair to enforce that particular distribution on me when I know it is not in my actual interests. There may, as Dworkin notes, be a plausible independent argument for the justice of such a distribution, but it cannot be based on presumptions of consent based on judgments about antecedent interests. ${ }^{21}$

In the cases under consideration, it is clearly in the antecedent interests of all embryos to be part of natural procreation. However, it is only in the actual interests of those who survive to live a reasonable life. It is, therefore, clear that those embryos that die in the attempt do not have their actual interests served by the process. Of course, neither Savulescu nor I think that the embryo has any (or any significant) actual interests, so both of us think that the lottery of existence, whether sexual or artificial, is a good bet for embryos. Savulescu and I do not have to distinguish between antecedent and actual interests in these cases because for us there are no relevant actual interests. But this is not, I believe, true for those who think the embryo is one of us. They think it does have interests in life that must not be trifled with. So that, although the "business of natural procreation" might still be a good bet for embryos (a bet placed before the race is run), and a better bet (at that time) than the alternative, it is not clear that this defeats the idea that those who in fact must die to permit others to have reasonable lives are not treated instrumentally. As Dworkin has shown, their actual interests are not thereby served. Dworkin rightly observes, just as, "it cannot be just for you to force me to surrender the ticket for one hundred pounds even if is true that I would have consented to sell it to you for that sum had you asked me antecedently to the draw."

Those who think the embryo has rights and interests from conception cannot, therefore, straightforwardly justify the deaths of the unlucky embryos by reference to what was in their antecedent interests, nor even by what they might have agreed to at that time. Although Savulescu's appeal to antecedent interests is attractive, it is flawed. There is a real sense in which these embryos are used instrumentally, despite the plausible claims about their antecedent interests. Their instrumentality is not ascertainable ex ante but only once it is clear that they must die; only at that point do they perhaps become mere instruments. However, nothing Savulescu says shows that actual instrumentality is not real instrumen- 
tality, and even if Savulescu does not think it "wrongful instrumentality," embryo rightists certainly should because they think that at the time it dies the embryo has actual interests and they must think that these are either served or at least not harmed by the death of the embryo.

Again, I insist that, when we know that a practice involves the inevitable deaths of some, and the practice is accepted for the sake of the survivors (why else would we do it at all? ${ }^{22}$ ), then in a real and indefeasible sense, those who die die for the sake of those who survive.

One important reason for introducing the distinction between antecedent and actual interests is to demonstrate that, contra Savulescu, an embryo would see no advantage, gain no advantage, from existence in these circumstances. True, it would not be much disadvantaged from Savulescu's (and, for that matter, from my) perspective, but embryo rightists should, I believe, think differently about this case. Although one day of life for a very early embryo is clearly not worse than nonexistence (assuming a painless death), it is not a deal that an embryo would be anxious to strike antecedently, nor is it one that those who care about the embryo would judge to be so clearly in the embryo's interests that they should grasp it for the sake of the embryo. I am certainly not assuming that a short life is worse than nonexistence; simply that in this case it is not obviously significantly better, given that embryos this early experience nothing or nothing significant. However, again it must be emphasized that embryo rightists do regard this early embryonic life as valuable and the death even of these early embryos as bad as the death of any person.

I am not saying that actual interests trump antecedent interests. Rather, I am pointing out that, for those who value the embryo, who regard it as "one of us," the embryo's interests matter; and it is arguably their actual interests that matter, given that they are supposedly at that time full members of the moral community. This is a difficult exercise for those who do not think the embryo has any interests because they, like Savulescu and I, naturally think that they have taken the interests of the embryo into account and no interests have been harmed. Rather, we have to imagine what it would be for the embryo to have an interest in life, which was created only to be cruelly frustrated. The purpose of my paper was to try to determine what those who think like this must think consistently about both natural procreation and the creation of embryos in pursuit of other goals.

\section{Nonviable Embryos Gain Nothing from the "Chance" of Existence}

A high proportion of the early embryos that are lost as part of sexual reproduction would have been nonviable from the start, doomed to a very early death from conception because their genetic constitution is incompatible with survival. Although this fact does not make a difference to their moral status, $^{23}$ it does show that the practice of human reproduction was never in their interests, for they never had a chance. They, probably the majority of the early embryos that are lost in sexual reproduction, both antecedently and actually were always instrumental to the creation of viable embryos because they would never have been chosen for existence in their own right, for their own sake.

Suppose sexual reproduction worked slightly differently. ${ }^{24}$ Instead of five embryos being created and dying very early on in their existence for every 
healthy child born, those five individuals died after one day of postnatal life. This fact should make no difference to embryo rightists, but it is surely doubtful that it would be regarded by Catholics or prolife groups as anything other than wickedly irresponsible to create so many infants that would live only for a day. Or suppose instead of such loss of infant life attending the successful birth of all healthy children it attended the birth only of the healthy children of say $15 \%$ of the world's population. Would the reproductive choices of these people be a matter of moral indifference to those who think that the loss of five of us is a reasonable and responsible thing to bring about to produce healthy children?

We now need to consider the extent to which sexual reproduction raises issues similar to those considered in "The Survival Lottery." This is pertinent because much of the argument turns on the question of whether the fact that a risk of death that increases the chances of survival not only of the individual who dies but of the population to which the individual belongs makes the imposition of that risk justifiable.

\section{The Survival Lottery}

This argument presupposed that organ transplants are a very safe procedure for all organs - the same risks as tonsillectomy. In such circumstances, wherever five people can be saved by organ transplants and no other sources of organs are available, it would be rational and prudent for a society, and all the individuals in it, to adopt the survival lottery (SL). Every member of society is given a lottery number and, where five-plus lives can be saved if one is killed and his organs distributed, a number is picked at random and the bearer of that number is killed. The SL is both rational and prudent; it is in everyone's interests because it reduces their chances of premature death. Nonetheless, most people are against it; not least because they regard it as unjustifiable homicide. ${ }^{25}$

The survival lottery, of course, to which I return in a moment, is different in that it depends for its plausibility on its acceptance by the community in which it would operate, on its satisfaction of the prudential and moral interests of the participants in the lottery. The exact parallel with sexual reproduction would be a survival lottery applied to children below the age of consent; for here, those who think such children are "of us" must decide what to do for them that best protects their rights and interests and gives them the best chance of life.

\section{The Survival Lottery Revisited}

\section{Savulescu concludes by saying:}

Does destructive research impose unreasonable risk on the embryo? There are two ways in which we can avoid violating a principle of nonmaleficence. The first is to argue that the embryo is not the kind of being that can be harmed by being killed. This is to deny that the embryo has a moral status.

The second is to argue that the embryo that is killed has not been exposed to an unreasonable risk. I have argued, after Harris [note 2: Harris J. Survival lottery. In: Harris J, ed. Bioethics. New York: Oxford University Press; 2001: 300-15.], that if the embryo is a part of a population of embryos that will benefit from a practice of killing some, then killing may not be wrong [note 3: Savulescu J. The embryonic stem cell lottery and the cannibalization of human beings. Bioethics 2002;16(6):50829.]. Whether it is wrong turns on the fraction of ART embryos that are killed and what the benefits are to that population. If stem cell therapies will ben- 
efit that population in significant ways, then this may be enough to justify killing some.

Contra Savulescu, I had attempted a third way, although I accept, and have elsewhere argued for, both of Savules$\mathrm{cu}^{\prime}$ 's solutions. My third way was to attempt to show that, because natural sexual reproduction is accepted by all of those who are not attracted to the first two ways, they either have to renounce sexual reproduction or accept that sacrificing embryos for a moral purpose comparable in moral importance with that of creating a new child is also justifiable. Despite Savulescu's ingenious arguments, I still think this third way is viable and that it adds to the strength of the other two that both he and I accept and rely on.

However, when Savulescu asks: "Does destructive research impose unreasonable risk on the embryo?" and answers by suggesting that "there are two ways in which we can avoid violating a principle of nonmaleficence," he points out (and indeed concedes) that it is also only these two ways that can rescue embryo research from the charge that it involves unacceptable maleficence. I believe that these are also the only two ways in which sexual reproduction could be made acceptable to embryo rightists, because sexual reproduction involves the voluntary acceptance of the deaths and instrumental use of embryos. Embryo rightists must, I believe, abjure sexual reproduction, find another justification for it, or concede that experiments on and use of embryos for comparably serious moral purposes are acceptable, which was precisely my claim.

When Savulescu says

I have argued, after Harris, that if the embryo is a part of a population of embryos which will benefit from a practice of killing some, then killing may not be wrong, whether it is wrong turns on the fraction of ART embryos which are killed and what the benefits are to that population. If stem cell therapies will benefit that population in significant ways, then this may be enough to justify killing some.

I agree wholeheartedly, but he has thereby conceded the very point of mine against which he has directed so much brilliance. For this is the survival lottery! And whereas I have always defended its compelling rationality, no embryo rightists nor indeed most other people (apart, dare I claim, from Savulescu and myself) are remotely attracted to it.

\section{Instrumentalization Again}

Savulescu and I agree that, if something will benefit a particular population in significant ways, then this may be enough to justify killing some members of that population for the benefit of others. So, although sexual reproduction does not involve the direct killing of embryos, the deaths of $80 \%$ of the embryos that are created in sexual reproduction are justified, according to both Savulescu and myself, because those deaths benefit the population of embryos in significant ways. If killing some members of the relevant population would be justified, then a fortiori creating similar numbers who must die prematurely is justifiable. The only remaining question is whether this instrumentalizes those created only to die. On this point Savulescu and I continue to differ.

In the survival lottery, something that can legitimately be characterized as deliberate killing, and also as instrumentalizing those who die for the benefit of those who live, inexorably takes place. Of course, sexual reproduction is different. Savulescu is trading on 
the idea that, because none of the candidate population will exist without the practice of sexual reproduction, and one-fifth of those created will survive, it is, like procreation in conditions of high infant mortality, fully justified. I agree with Savulescu that it is fully justified and justifiable conduct, but then I have no reason to disagree with him about this-after all, I invented the survival lottery! The question, however, is whether it is justifiable conduct for those who think that deliberately creating a life to protect other lives, or deliberately creating a life that will not come into being as a human person but is destined only to die, is justifiable. As I have noted, embryo rightists usually object to IVF and to the creation of "spare" embryos for just this reason, so they should consistently object to the creation of spare embryos as a result of sexual procreation.

I believe I have shown that sexual reproduction is like other unacceptable (to many) practices that involve instrumentalization and a forbidden type of killing (or of the deliberate ending of the lives) of the innocent. My main point has been that sexual reproduction creates doomed spare embryos in ways sufficiently analogous to assisted reproduction technology (ART) to make sexual reproduction unacceptable if ART is unacceptable. Savulescu's response commits him to the view that "if the embryo is a part of a population of embryos that will benefit from the practice of killing some, then killing may not be wrong. Whether it is wrong turns on the fraction of ART embryos that are killed and what the benefits are to that population." Again, I agree. But, whereas Savulescu insists that in sexual reproduction no embryos are killed and that this makes it different, I insist that sexual reproduction does involve delib- erate sacrifice of embryos and, therefore, that it amounts to the same thing. We disagree in that Savulescu thinks that, because it is not an unreasonable risk of death for the embryos, it is not somehow deliberate sacrifice of embryos in a way that embryo rightists, in other contexts, disapprove of. The beautiful woman ${ }^{26}$ that has distracted Savulescu's attention here and prevented him from keeping his eyes on the prize is someone we both admire; she is the idea that sacrifice of life is justifiable if the gains are of sufficient moral importance.

Let me finish by discussing three fairly exact analogies to sexual reproduction that I believe Savulescu is already committed to accepting or that he ought (morally and logically) to accept. None of these analogies is acceptable to embryo rightists. The first is a survival lottery for children below an age that they can make autonomous decisions for themselves. If the assumptions of the survival lottery are rightthat all who participate would, because of their participation, have a better chance of living to a ripe old age than they would in a community without the survival lottery or with parents that did not enter them in the lotterythen not only is the lottery in all those children's interests, but it is also obvious that a caring and good parent would be right to include their child in the lottery and wrong not to. The SL for kids is ethical and passes the Savulescu test that I adapt here: If the child is a part of a population of children that will benefit from a practice of killing some, then killing may not be wrong, whether it is wrong turns on the fraction of children that are killed and what the benefits are to that population. I think this is the situation with natural reproduction and therefore that embryo rightists, if they maintain their commitment to sexual 
procreation, must consistently accept the survival lottery for children, or, more likely, if they reject the SL for children, they must renounce sexual reproduction.

The second analogy is one I considered in my earlier paper. Here, I adapt it slightly so that the numbers cohere with the ratio I have been using, but again nothing turns on the precise ratio so long as it is advantageous.

In normal sexual reproduction, embryos must be created only to die so that a sibling embryo can come to birth. Arguably, it is in each embryo's interest that reproduction continues because it is its only chance to be the one that survives. Embryos (if they had rationality) would have a rational motive to participate (albeit passively) in sexual reproduction. By contrast, so it might be claimed, embryos produced specifically for research would not rationally choose to participate for they stand to gain nothing. All research embryos will die, and none have a chance of survival. If this argument is persuasive against the production of research embryos, it is easily answered by ensuring that the production of research embryos to some appropriate extent mirrors that of the production of embryos in normal sexual reproduction. One would simply have to produce more embryos than were required for research, randomize allocation to research, and ensure that the remainder were implanted with a chance to become persons. To ensure that it was in every embryo's interest to be "a research embryo," all research protocols permitting the production of research embryos would have to produce extra embryos for implantation. For every, say, 100 embryos needed for research, another 20 would be produced for implantation. The $100 \mathrm{em}-$ bryos would be randomized (80 for research, 20 for implantation), willing mothers would have been identified in advance, and all embryos would have a chance of survival and an interest in the maintenance of a process that gave them this chance.

This is a true parallel with natural reproduction (the exact numbers are unimportant). Here, it is in the ex ante interest of all embryos not otherwise created for reproduction to be part of the population of research embryos. It is in all their interests because it is their only chance of having a life. Of course, it is not in the actual interests of those not implanted. Embryo rightists will (and do) object, but if and when they object, they are inconsistent with their views on natural procreation. In consistency and by parity of reasoning, they must object to natural procreation if they object to this variant of the creation of research embryos.

Embryo rightists would reject any such proposal because, apart from the unacceptable direct killing, in a real sense it instrumentalizes the entire population of embryos. All are created for a purpose, and the survival of the $20 \%$ implanted does not defeat the instrumentalizing motives for which they were created; although, of course, they are not exclusively a means to those ends but ultimately become ends in themselves.

The third, slightly imperfect analogy is the survival lottery as originally conceived. This analogy is imperfect because, given that it applies to all members of the society, it includes a large proportion of people who can and must consent to its implementation.

These three cases are relevantly similar to sexual reproduction, and all share with sexual reproduction the fact that they pass the Savulescu test for permissibility-namely, that just as "natural reproduction gives every embryo the greatest chance it could 
have of becoming a baby," so in each of these cases the members of the relevant population are given the greatest chance they could have of survival. Each case is like sexual reproduction in that the relevant practice involves the voluntary creation and/or destruction of individuals for the sake of some greater good, and hence in each case those who do such a thing are responsible for the voluntary (though not necessarily intentional or enthusiastic) bringing about of those deaths. Significantly, I believe, of the four cases only sexual reproduction is currently acceptable to embryo rightists, although it is my contention that this involves an inconsistency that must be resolved. In each of the four cases, the deaths are in a real sense instrumental, necessary for the greater good, envisaged, foreseen, and voluntarily countenanced for that very reason. In each case, of course, there are survivors who become ends in themselves. In none of the cases is membership of the population "at risk" in the actual interests of those who die; although in all cases membership of the population is in the ex ante interests of all. Those who think that in each case all members of the population at risk have interests in life that must be respected, have or should have problems with the practice independently of the issue of instrumentalization. Only the original survival lottery can, through consent of the at-risk population, partially mitigate the claim that their interests in life are thereby violated. Even in the case of the original survival lottery, though, this will not be enough for those who think that life is intrinsically valuable and who believe that this value cannot be voluntarily forgone.

Finally, of course, most embryo rightists would differ from Savulescu and me in that they deny that there is any so-called direct killing involved in sex- ual reproduction. Of course, neither is there necessarily in the creation of spare embryos as part of ART (they may simply die because they are not implanted or not cryopreserved), although embryo rightists nonetheless object, and not solely, I believe, on the grounds that instrumentalization is involved. It is worth ending by remembering a scenario envisaged in my original paper. Suppose the use of IVF had been perfected to the point where only one spare embryo was required for every live birth, which gives a much more favorable survival ratio than sexual reproduction. In such a case, we will suppose that only one spare embryo that would not survive was required for every live birth via IVF whereas the survival ratio for sexual reproduction remained one in five. Such an improvement in IVF would seem to make using IVF mandatory for embryo rightists, even though they would still be doing wrong according to their own beliefs! It is interesting that embryo rightists are not investing heavily in IVF to this end in the hope that sexual reproduction could be replaced by an embryo-sparing method of reproduction. ${ }^{27}$

\section{Notes}

1. My colleague Maurizio Mori (personal communication) gives the following account of the origin of the expression "the embryo, one of us":

The story is the following: It was used by Prof. Francesco D'Agostino, Chair of the Italian National Ethics Committee, when he presented the result of the Report of the Italian National Committee for Bioethics to the media in 1996. He said more precisely that the Committee had stated that "the human embryo is to be treated as one of us."

Of course, it was immediately shortened to the more famous form. There is, however, at 
least one book with such a title: Concetti G. L'embrione uno di noi. Rome: Vivere In; 1997.

2. I say "very first act" because obviously all babies that result from sexual reproduction result from a single act of intercourse. If there have been others in a different cycle, there have probably been early miscarriages. Robert Winston gave the figure of five embryos for every live birth some years ago in a personal communication. Anecdotal evidence to me from a number of sources confirms this high figure, but the literature is rather more conservative, which makes more probable a figure of three embryos lost for every live birth. See: Boklage CE. Survival probability of human conceptions from fertilization to term. International Journal of Fertility 1990;35(2):75-94. See also: Leridon H. Human Fertility: The Basic Components. Chicago: University of Chicago Press; 1977. Again, in a recent personal communication, Henri Leridon confirmed that a figure of three lost embryos for every live birth is a reasonable conservative figure.

3. Savulescu J. Embryo research: are there any lessons from natural reproduction? Cambridge Quarterly of Healthcare Ethics 2004;13(1):68-75.

4. Like Savulescu, I am happy to ignore the problem of attributing rationality to brainless entities.

5. See: Harris J. Pro-life is anti-life: the problematic claims of pro-life positions in ethics. In: Häyry M, Takala T, eds. Scratching the Surface of Bioethics. Amsterdam: Rodopi; 2003.

6. See, for example: Kahn A. Clone mammals .. clone man. Nature 1997;386:119. Also, see my responses: Harris J. Is cloning an attack on human dignity? Nature 1997;387: 754; Harris J. Cloning and bioethical thinking. Nature 1997;389:433.

7. Emphasis added.

8. Savulescu (personal communication) is perhaps one exception. He claims that, provided couples would raise the first embryo as a baby and love it, if it miraculously survived, and this is their primary intention, then they are not intending the death of the embryo in the relevant sense, though they do foresee it.

9. Savulescu J. Personal communication.

10. Feinberg J. Harm to Others. New York: Oxford University Press; 1984. See especially pp. 102-4.

11. See: Harris J. Wonderwoman and Superman. New York: Oxford University Press; 1992: chap. 4. See especially pp. 84-92.

12. Savulescu J. Personal communication.

13. See note 13 , Savulescu.
14. This is not far from some of the material facts of a real recent case. See: Harris J. Conjoined twin non-persons. Medical Law Review 2001;9 (3):221-36. I have clarified this case in the light of comments from Julian Savulescu.

15. For an elaboration of this concept of instrumentalization, see note 12, Harris 1992:122-7.

16. Savulescu J. Personal communication.

17. For a precise explanation why, see note 15 , Harris 2001.

18. Elsewhere I have given an account of exploitation that gives more substance to Kant's ideas, but it does not apply to the case of those who, like embryos, cannot give consent or adopt the projects of others as their own. See note 12, Harris 1992:98-139. Savulescu (personal communication) objects that, even if this is the correct account of instrumentalization, it cannot be the correct account of wrongful instrumentalization. This account would imply that an artist drawing a baby or photographing an unrecognizable part of a baby's body was necessarily wrong because it was instrumentalization. However, determining if this use of a baby is wrong turns plausibly on whether its parents or legal guardians consent to it or on whether the act harms the baby.

19. According to Savulescu, it may negate the charge of wrongful instrumentalization (personal communication).

20. I hope the irony does not need stress here.

21. See: Harris J. More and better justice. In: Mendus S, Bell M, eds. Philosophy and Medical Welfare. New York: Cambridge University Press; 1988:75-97.

22. I do not want to talk here about sexual gratification as a motive. No sex, pleasewe're British!

23. Neither for Savulescu nor for I; nor for embryo rightists.

24. I am grateful to Julian Savulescu for the first part of this suggestion.

25. See: Harris J. The survival lottery. Philosophy 1975;50(191):81-8. It is reprinted inter alia as detailed in: Savulescu, this issue, note 2 .

26. For Savulescu and the properties of beautiful women, see: Savulescu, this issue.

27. Of course, embryo rightists should abjure sexual reproduction altogether; but if they did judge the creation of doomed embryos as justifiable in pursuit of the creation of new life, the embryo-sparing ART would seem to be the best. Here again, Savulescu would differ, believing that embryo rightists would only be committed to improving the survival chances of an individual embryo by interventions in that particular embryo. 
The Creation Lottery: Final Lessons from

Natural Reproduction: Why Those Who Accept

Natural Reproduction Should Accept Cloning and Other Frankenstein Reproductive Technologies

\author{
JULIAN SAVULESCU and JOHN HARRIS
}

Opponents of destructive embryo research, such as embryo rightists, as well as proponents accept that natural reproduction is permissible. There is an alternative to natural reproduction - to remain childless. John Harris began this series of articles by asking, what does a commitment to the permissibility of natural reproduction entail? Harris has argued that a commitment to the permissibility of natural reproduction entails a commitment to the permissibility of destructive embryo research. Julian Savulescu has denied this. However, there are significant areas in which our views have converged.

What are some of the potentially relevant moral features of natural reproduction?

1. Natural reproduction involves a very high rate of embryo loss. We have assumed that four out of five embryos perish during attempts at natural reproduction. ${ }^{1}$

2. These deaths are an unavoidable part of natural reproduction. Some of these are genetically abnormal and could never survive. But some will be genetically normal and could have survived, if uterine or other conditions were different. However, the deaths of these embryos are unavoidable given the current state of knowledge.

3. There is an alternative to natural reproduction: childlessness through contraception or abstinence.

4. Natural reproduction is voluntary.

The precise fraction of embryos that perish during natural reproduction is not crucial. Even if $99 \%$ of embryos perished during natural reproduction, embryo rightists and other defenders of natural reproduction would go on regardless. What is crucial is that the practice necessarily involves some embryos dying and some surviving. Harris has argued that those that die are instrumentalized for the purposes of ensuring the survival of others. Savulescu has denied this.

However, we both agree that natural reproduction is a creation lottery. Natural reproduction is a practice that involves the creation of a population of embryos for the purposes of creating a new human being and that involves the unavoidable death of $80 \%$ of those embryos, where the alternative to this practice is not to create any new human beings. To put this more generally, a creation lottery involves the creation of a population of embryos for the purpose of creating a new human being, and this practice involves the unavoidable death of some of these embryos. Those, such as embryo rightists, who believe that natural reproduction is permissible are logically committed to the permissibility of running creation lotteries.

There are other relevantly similar creation lotteries. 


\section{Assisted Reproduction}

Imagine that assisted reproduction (AR) necessarily required, as a part of its very nature, the production of spare embryos. That is, it was a necessary part of AR that spare embryos be created. Then, AR would be permissible or at least the fact that spare embryos that were destined to die were created would not constitute an objection to $\mathrm{AR}$ if one accepted the permissibility of natural reproduction. In the early days of AR, this was possibly true. Today, embryo-sparing techniques of AR are possible. That is, it is possible to create embryos for AR without producing spare embryos. Thus, the deaths of spare embryos are avoidable. AR is not a creation lottery.

There are two points to note about this. First, the use of embryo-sparing techniques is parasitic on the progress and development of AR through the past production of spare embryos. For those who see the creation of spare embryos as evil, such as embryo rightists, the practice of engaging in embryosparing AR is parasitic on a past evil practice. If embryo rightists do not believe that we can benefit from past evil, as they typically do not, embryo rightists should oppose even embryosparing AR.

Second, although it is possible to conduct AR without the production of spare embryos, it exposes women to a higher risk through multiple stimulations and procedures. There is a strong moral reason to create spare embryos and their creation is morally unavoidable, if one is to conduct AR. Under such circumstances, production of spare embryos during $\mathrm{AR}$ is like natural reproduction.

The current practice of AR involving spare embryos is not strictly a creation lottery identical in kind to natural reproduction. The deaths of spare embryos are avoidable, given the current state of knowledge. However, we could refine the idea of what constitutes a creation lottery. We could change "unavoidable" to "unavoidable"," where "unavoidable ${ }^{* \prime \prime}$ is defined as "given the current state of the world including knowledge, values, and intentions of human agents." On this revised definition of a creation lottery, AR would be a creation lottery. The reason is that the destruction of embryos during conventional ART would be unavoidable* because the values (in particular, the weight given to the welfare of women) makes it unavoidable. We cannot argue in this short piece that "unavoidable*" is as plausible as "unavoidable," but we believe it is.

At the very least, where the production of spare embryos-embryos in excess of those that will be implanted-is a necessary part of some particular procedure in $\mathrm{AR}$, then that procedure is a creation lottery of the kind similar to natural reproduction. It would be permissible.

\section{The Voluntary Assignment of Embryos to Research as a Condition of Procreation}

Suppose a couple contemplating AR were of a mind to avail themselves of this technology only on the condition that some of the embryos created for their use were from the start assigned to research or therapeutic uses. They agreed that they would not reproduce at all (or would not again reproduce) unless, say, two of the ten embryos created for their use were assigned to research. In such a case, all the embryos benefit from the couple's decision because none of them would otherwise have been created. And it is a lottery, just as in natural reproduction, which embryos will have a chance of surviving and which will not. The entire population of embryos has a 
good chance of existence, and this is their only chance of existence. This would be like natural reproduction in that the practice itself constitutes the only circumstances in which any of these embryos would come into existence and would constitute a chance for all. No one accepting natural sexual reproduction would have a reason to object to this practice, and so it would, presumably, constitute an ethical source of research and therapeutic embryos for embryo rightists.

\section{Acceptance of Natural Reproduction Implies the Permissibility of Reproductive Cloning}

Reproductive cloning aims to produce a human being by cell nucleus replacement. If cloned human beings have the same moral status as other human beings, and we can see no reason why they should not, then striking implications follow.

One of the major objections to any current attempt to clone a human being is that, in the case of Dolly (the first cloned mammal), only one clone was successfully produced after 277 attempts. Cloning is inefficient and involves very high embryo wastage.

But embryo wastage per se cannot be an objection to reproductive cloning for those who accept natural reproduction. After all, somewhere around $80 \%$ of embryos perish in natural reproduction! Reproductive cloning is a creation lottery of the same kind as natural reproduction. The fact that many embryos might perish as a result of our attempting to clone a human being is no objection to reproductive cloning.

Not only is natural reproduction inefficient, it is also unsafe. Approximately $3-5 \%$ of babies born have some abnormality. Natural reproduction not only involves the foreseeable and unavoidable creation of some embryos that will die but also some embryos that will go on to become very disabled human beings. Many embryos created are so genetically abnormal that they die, but some survive only to die as grossly deformed babies. The branch of medicine known as "teratology" bears witness to the imperfection of natural reproduction-babies born with missing limbs, with a missing brain, or with two heads. Thus, the definition of a permissible creation lottery should be extended to include the creation of disabled human beings. (Natural reproduction is, of course, also dangerous for the mother. It is well established that carrying a child to term is more dangerous for the mother than early abortion and much more dangerous than not having a child at all.)

A creation lottery involves the creation of a population of embryos for the purpose of creating a new human being, and this practice involves the unavoidable death of some of these embryos and the unavoidable production of grossly deformed and disabled human beings.

Cloning is associated with high rates of embryonic loss and birth abnormalities. ${ }^{2}$ The strongest and one of the most common objections to reproductive cloning is that it is unsafe. ${ }^{3}$ As Catholic Archbishop George Pell put it in the Sunday Telegraph in Australia in 2001, "The process used to create Dolly the sheep and other clones has involved a disastrous number of miscarried and monster lambs."

For those who accept natural reproduction, however, there is no objection to reproductive cloning on grounds of inefficiency or lack of safety. Even if attempts at reproductive cloning involve many embryos that will perish in early embryonic development and others that go on to be grossly deformed human beings, this is no different than natural reproduction. They are both relevantly similar creation lotteries. 
This is a striking conclusion. Acceptance of natural reproduction entails acceptance of reproductive cloning, at least from the perspective of the safety and efficiency of the practice.

\section{New Forms of Reproduction}

In theory, there are many ways to reproduce other than by the current techniques of in vitro fertilization and nuclear transfer. Let us call these, together with reproductive cloning, Frankenstein reproductive technologies. For example, parthenogenesis might result in the creation of a human being from a single egg. It is theoretically possible to combine the genetic material of two females in a human egg and cause this genetic material induced to segregate into sex chromosomes that would recombine to form a female embryo. ${ }^{4}$ The relatively recent technique of "haploidization" enables us to take an adult cell (male or female), divide its genetic material in half, use the 23 chromosomes from one half to act as a "sperm" to fertilize an egg, and combine these with the 23 chromosomes in the egg.

Many of these new forms of reproduction would have a high embryo loss rate and a risk of producing genetically abnormal human offspring. However, where the embryonic death and the production of genetically or otherwise abnormal human beings is a necessary and unavoidable part of the process, then these are creation lotteries. That is, for those who accept natural reproduction, the embryo wastage and risk of deformity cannot be an objection to these lotteries.

This does not necessarily imply that these forms of reproduction or cloning are all things considered permissible. There might be social reasons to object to them or objections based on the just allocation of scarce resources. What it does imply, however, is that those who accept natural reproduction cannot appeal to the lack of safety or efficiency of such procedures, given that they are creation lotteries of a kind similar to natural reproduction.

\section{The Return to Natural Reproduction?}

We have argued that creation lotteries similar to natural reproduction are permissible even if they involve high embryo loss rates and monstrous abnormalities. Some embryo rightists and other conservatives are liable to resort to the following obvious objection.

The main alternative to natural reproduction is childlessness. But there is an alternative to monstrous Frankenstein reproductive technologies such as cloning-natural reproduction. Insofar as the loss rate of natural reproduction and/or the deformity rate are lower in natural reproduction, natural reproduction is a preferable creation lottery.

This objection may be valid. We say "may" because each creation lottery involves the creation of a different population that would not otherwise exist-it is not at all obvious that it is preferable to create superior but different populations of people. We have argued elsewhere that we do have a moral obligation to produce the best people. ${ }^{5}$ We have a moral obligation to use genetic testing to select the best children that we could have. But many people deny this. Those who deny we have an obligation to create the best people-that is, people with the longest and best-quality lives - would have no objection at all to the Frankenstein reproductive technologies on the basis of safety or efficiency.

But if it is valid, it has a very striking consequence. If the Frankenstein technologies become more efficient or safer than natural reproduction (i.e., would have a lower embryo wastage 
or fewer deformities), then they would be preferable to natural reproduction. If cloning were ever to become more efficient than natural reproduction, then we would have a moral obligation to clone.

This is not so farfetched. It is possible that evaluation of sperm quality and sperm sorting together with intracytoplasmic sperm injection (ICSI) might yield higher embryo survival rates than the natural rate of about $20 \%$. If that were ever the case, we would, if this objection is correct, have an obligation to use sperm sorting and ICSI rather than natural reproduction.

So, either there is no objection to Frankenstein reproductive technologies (on grounds of inefficiency or dangerousness) or else, under certain circumstances, we will have a moral obligation to employ them.

\section{Priority for the Natural?}

There is one last way in which those who favor natural reproduction as a method of procreation might respond. They might claim that the fact that natural reproduction is natural is morally relevant and makes it superior to artificial methods of reproduction. We should give priority to the natural over the artificial.

This is a commonly held value. Witness the obsession with natural foods over genetically modified and other artificial, Frankenstein foods. The belief that the natural should have priority over the artificial, though common, is mistaken. A child born by assisted reproduction is of the same kind with the same moral status as a child born by natural reproduction. Insofar as naturally occurring foods are safer or healthier, there is a reason to prefer them. In many cases, though, artificial preparations are healthier and safer. Indeed, they are preferred. The drug digoxin is used for heart conditions. It is always given in a highly purified pharmaceutical form as digoxin even though it occurs naturally as digitalis in the foxglove plant. Natural reproduction may be more fun than artificial reproduction. That is a reason to prefer it. Natural processes may be less costly or do less damage to the environment. These are reasons to prefer them. But there is no reason to prefer a natural process per se to an artificial process. The mere fact that something is natural is not a reason to prefer it.

The natural per se is morally neutral. Sometimes natural events are good, like a brilliant sunset or an abundant harvest. But often the natural does great harm - disease, pestilence, floods, hurricanes, fire, landslides, and the like can cause massive loss of human life. One might characterize the practice of medicine as the comprehensive attempt to frustrate the course of nature, because people naturally fall ill, are invaded by natural organisms like viruses and bacteria, and naturally die at a young age, often as babies. If we always prioritized the natural, we would have to abjure the practice of medicine and the discoveries of medical science, including vaccines and antibiotics.

Our current fascination and worship of the natural should be tempered. We should remember how Thomas Hobbes so famously described life in a state of nature:

And which is worst of all, continual fear, and danger of violent death; and the life of man, solitary, poor, nasty, brutish and short. ${ }^{6}$

\section{Method in Bioethics}

We believe that bioethics is about reason and argument. This series of papers began by trying to understand what a commitment to natural reproduction logically entails.

The process of bioethics involves constructive rational discourse. We have begun with very different points of 
views on this question. Through a somewhat tortuous process of reason and argument we have found where we differ but, more importantly, also where we converge.

Both of us have tried to see openly what the strengths and weaknesses of the other's arguments are. Through a process of dialogue, we have sought to gain insight into the logical entailments of an acceptance of natural reproduction. This has led us to striking conclusions that we both accept.

Bioethics is disappointing for its lack of constructive dialogue. Bioethics is not about conversion (that is the province of religion) or convincing others that one is right. It is about discovery of the truth and gaining knowledge. Sometimes it requires the revision of one's own beliefs. We acknowledge there are many mistakes remaining in our discourse. We present it rough and largely uncut, much as it has occurred, as an example (albeit far from perfect) of method in bioethics. ${ }^{7}$

\section{Notes}

1. Robert Winston gave the figure of five embryos for every live birth some years ago in a personal communication. Anecdotal evidence to John Harris from a number of sources confirms this high figure, but the literature is rather more conservative, making more probable a figure of three embryos lost for every live birth. See: Boklage CE. Survival probability of human conceptions from fertilization to term. International Journal of Fertility 1990;35:75-94. See also: Leridon H. Human Fertility: The Basic Components. Chicago: University of Chicago Press; 1977. Again, in a recent personal communication, Henri Leridon confirmed that a figure of three lost embryos for every live birth is a reasonable conservative figure.

2. Reprogramming cell fate: transgenesis and cloning. [Special issues.] Reproduction, Fertility, and Development 1999;10(7,8).

3. National Bioethics Advisory Commission. Cloning Human Beings. Washington, D.C.: National Bioethics Advisory Commission; 1997.

4. Trounson AO. What if there is a "sunset clause" on the $\mathrm{Y}$ chromosome? a view on reproductive technologies in the future. Medical Journal of Australia 1999;171:660-2.

5. Harris J. The Value of Life. London: Routledge; 1980; Harris J. Wonderwoman and Superman. New York: Oxford University Press; 1992. Savulescu J. Procreative beneficence: why we should select the best children. Bioethics 2001;15:413-26.

6. Hobbes T. Leviathan. Oakeshot M, ed. Oxford: Blackwell; 1960:82.

7. After a difficult and fractious courtship, we have both learned to love or at least admire the perfection of one goddess - the creation lottery. Those who believe that natural reproduction is permissible are committed to the worship of this goddess. They are committed to the permissibility of cloning and other Frankenstein reproductive technologies. 